\title{
Intracellular domains of amyloid precursor-like protein 2 interact with CP2 transcription factor in the nucleus and induce glycogen synthase kinase-3 $\beta$ expression
}

\author{
Y Xu ${ }^{1,2,5}$, H-S Kim ${ }^{1,5}$, Y Joo ${ }^{1}$, Y Choi ${ }^{1}$, K-A Chang ${ }^{1}$, C H Park ${ }^{1}$, K-Y Shin ${ }^{1}$, S Kim ${ }^{1}$, Y-H Cheon ${ }^{3}$, T-K Baik ${ }^{3}$, J-H Kim ${ }^{4}$ and Y-H Suh, ${ }^{*, 1}$
}

Amyloid precursor protein (APP) is a member of a gene family that includes two APP-like proteins, APLP1 and 2. Recently, it has been reported that APLP1 and 2 undergo presenilin-dependent $\gamma$-secretase cleavage, as does APP, resulting in the release of an $\sim 6 \mathrm{kDa}$ intracellular C-terminal domain (ICD), which can translocate into the nucleus. In this study, we demonstrate that the APLP2-ICDs interact with CP2/LSF/LBP1 (CP2) transcription factor in the nucleus and induce the expression of glycogen synthase kinase $3 \beta$ (GSK-3 $\beta$ ), which has broad-ranged substrates such as $\tau$ - and $\beta$-catenin. The significance of this finding is substantiated by the in vivo evidence of the increase in the immunoreactivities for the nuclear C-terminal fragments of APLP2, and for GSK-3 $\beta$ in the AD patients' brain. Taken together, these results suggest that APLP2-ICDs contribute to the AD pathogenesis, by inducing GSK-3 $\beta$ expression through the interaction with CP2 transcription factor in the nucleus.

Cell Death and Differentiation (2007) 14, 79-91. doi:10.1038/sj.cdd.4401928; published online 28 April 2006

The pathology of Alzheimer's disease (AD) is characterized by the deposition of neuritic plaques, of which the principal components are 40 and 42 amino-acid amyloid beta peptides (A $\beta$ ) derived from amyloid precursor protein (APP). ${ }^{1}$ APP belongs to a family of conserved type I transmembrane proteins including Apl-1 in Caenorhabditis elegans, ${ }^{2}$ Appl in Drosophila, ${ }^{3}$ and APP, ${ }^{4}$ APP-like protein 1 (APLP1) ${ }^{5}$ and APLP2 $2^{6,7}$ in mammals.

APLP1 and 2 display substantial amino-acid and domain homologies with APP. Although they do not have an $\mathrm{A} \beta$ domain, their intracellular C-terminal domains (ICDs) are highly similar to that of APP. ${ }^{8}$ APLP1 is known to be implicated in synaptogenesis, ${ }^{9,10}$ and recombinant APLP2 possesses an ability to promote neurite outgrowth. ${ }^{11}$ However, their physiological roles in neurons are still not fully understood. In the brains of AD patients, APLP2 immunoreactivity has been detected in a subset of neuritic plaques, ${ }^{12}$ suggesting that APLP2 might be involved in the pathogenesis of AD.

APLP2 matures through the same secretory/cleavage pathway as $\mathrm{APP}^{7}$ and previously, APLP1 and 2 were reported to be processed by $\gamma$-secretase in a presenilin 1-dependent manner. ${ }^{8,10}$ The APLP family can be also cleaved by $\varepsilon-$ secretase to generate the ICD composed of the last 50 amino acids of APLPs C-terminus (C50). ${ }^{13,14}$ Moreover, the ICDs of APLP1 and APLP2 produced by $\gamma$-secretase enhanced Fe65dependent gene transcriptional activation, as have been reported for the APP intracellular domain (AICD). ${ }^{10}$
Fe65, which is known to be ones of the adaptor proteins for APP, contains three protein-protein interaction domains, a WW and two phosphotyrosine binding (PTB) domains. The PTB2 domain, which is located in the C-terminal half of the molecule, is responsible for the interaction between Fe65 and the cytosolic tail of APP through the YENPTY domain of APP. ${ }^{15}$

Here, we demonstrate that the ICDs of APLP2 (APLP2-ICDs: C57, C50) interact with CP2 transcription factor in the nucleus and induce glycogen synthase kinase $3 \beta$ (GSK-3 $\beta$ ) expression, whereas their point mutants with Y738G in the ${ }^{738}$ YENPTY $^{743}$, an Fe65 binding domain, do not. CP2 is a ubiquitously expressed $66-\mathrm{kDa}$ protein, which regulates several genes including GSK-3 $\beta .^{16}$ Polymorphic variation in the CP2 gene has been known to be one of the AD risk factors. ${ }^{17}$

We also provide in vivo evidence that the immunoreacitivities for C-terminal fragments (CTFs) of APLP2 detected by C12 antibody, which specifically recognizes the last 12 amino acids of APLP2 and for GSK-3 $\beta$ are significantly upregulated in the $A D$ brains.

\section{Results}

APLP2-ICDs are translocated into the nucleus in a Fe65dependent manner. At first, we confirmed whether APLP2ICDs were detectable in the nucleus after transfecting C57 or

\footnotetext{
${ }^{1}$ Department of Pharmacology, College of Medicine, National Creative Research Initiative Center for Alzheimer's Dementia and Neuroscience Research Institute, MRC, Seoul National University, Seoul, South Korea; '2Department of Preventive Medicine, Yanbian University College of Medicine, Yanj City, Jilin Province, China; ${ }^{3}$ Department of Anatomy, College of Medicine, Eulji University, Daejeon, South Korea and ${ }^{4}$ Department of Life Sciences and Division of Molecular and Life Sciences, Pohang University of Science and Technology, Pohang, Kyungbuk, Korea

${ }^{*}$ Corresponding author: Professor Y-H Suh, Department of Pharmacology, College of Medicine, National Creative Research Initiative Center for Alzheimer's Dementia, Seoul National University, Seoul, 110-799, South Korea. Tel: + 82-2-740-8285; Fax: + 82-2-745-7996; E-mail: yhsuh@ plaza.snu.ac.kr

${ }^{5}$ These authors contributed equally to this work.

Keywords: amyloid precursor-like protein 2; Alzheimer's disease; CP2 transcription factor; Fe65; GSK-3 $\beta$; $\tau$

Abbreviations: APLP, amyloid precursor like protein; APP, amyloid precursor protein; AICD, APP intracellular domain; A $\beta$, amyloid beta protein; AD, Alzheimer's disease; PTB, phosphotyrosine binding domain; GSK-3 $\beta$, glycogen synthase kinase-3 $\beta$; CTFs, C-terminal fragments; C57, C50, 57, 50 amino-acid residues carboxy

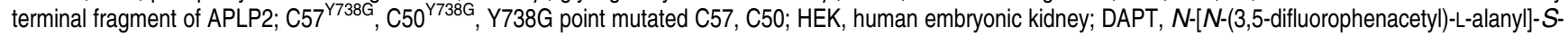
phenylglycine $\tau$-butyl ester; NGF, nerve growth factor; NFT, neurofibrillary tangle

Received 04.8.05; revised 26.1.06; accepted 01.3.06; Edited by P Nicotera; published online 28.4.06
} 
C50 (Figure 1B (a)) at 48-h post-transfection. APLP2-ICDs were detected in the nuclear fractions of $\mathrm{C} 57-$ or $\mathrm{C} 50$ transfected HEK293 cells using C12 antibody, which specifically recognizes the last 12 amino acids of the Cterminus of APLP2, not crossreacting with the C-terminus of APP ${ }^{18}$ or anti-GFP antibody (Figure 1B (a)). In addition, we also examined the distribution of APLP2-ICDs in the nuclear and cytosolic fractions of HEK293 cells co-transfected with Fe65 and either APLP2-ICDs or their point mutants (Y738G). The point mutation of $Y 738$ to $G$ in the ${ }^{738}{ }^{Y E N P T Y}{ }^{743}$ domain was reported to significantly impair Fe65 binding to APLPs. ${ }^{10}$ APLP2-ICDs were more abundantly detected in the nuclear fractions of $\mathrm{C} 57$ or $\mathrm{C} 50$ transfected cells than in the same fractions of the mock or the Y738G point mutants transcfected cells. By contrast, in the cytosolic fractions, relatively small amount of APLP2-ICDs was detected in the cells overexpressing APLP2-ICDs compared to the cells overexpressing their point mutants (Figure $1 \mathrm{~B}(\mathrm{~b}$ and $\mathrm{c})$ ). This result illustrated in Figure 1B (b) suggests that binding with Fe65 plays a role in nuclear translocation of APLP2ICDs, as proposed before. ${ }^{8}$ Next, the presence of APLP2ICDs was also found in the nuclear fractions of HEK293 cells overexpressing full-length APLP2-751 (Figure 1B (d)). The purity of the nuclear or cytosolic fraction was checked using anti-calnexin, anti- $\beta$-tubulin and anti-histone 3 antibodies (Figure 1B (a-d)).

We then investigated the subcellular localizations of APLP2-ICDs and their colocalization with Fe65 by confocal
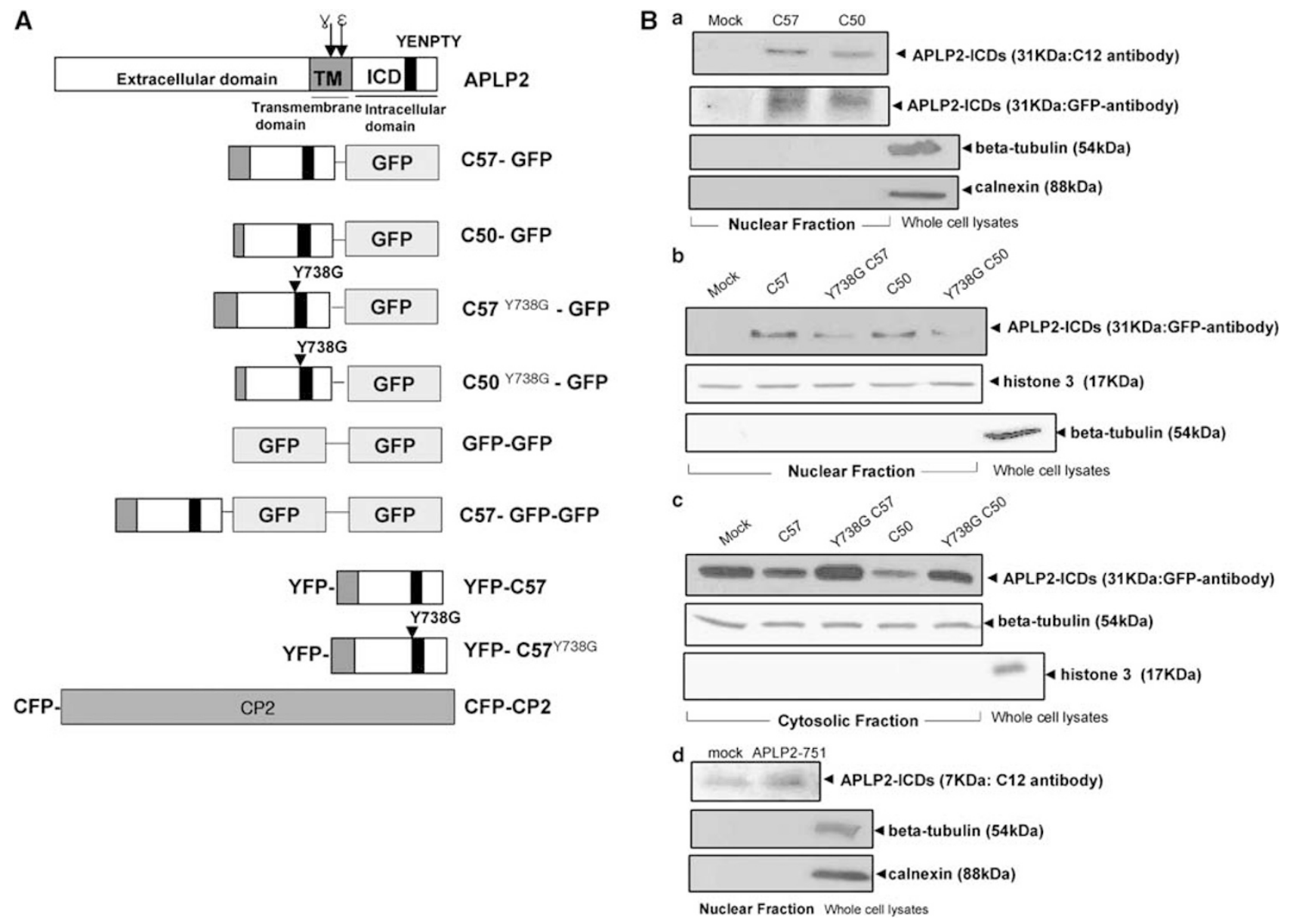

Figure 1 APLP2-ICDs are translocated into the nucleus in an Fe65-dependent manner. (A) Schematic representation of C57, C50 constructs, point mutated forms of C57 and $\mathrm{C} 50\left(\mathrm{C} 57^{\mathrm{Y7} 38 \mathrm{G}}, \mathrm{C} 5 \mathrm{O}^{\mathrm{Y7} 38 \mathrm{G}}\right)$ and CFP-CP2 constructs used in this study are shown. The ICDs of APLP2 $(\mathrm{C} 57, \mathrm{C} 50)$ are known to be generated by $\gamma$ - or $\varepsilon$-secretase cleavage after the ectodomain has been shed. (B) The presence of APLP2-ICDs was examined in the nuclear or cytosolic fractions of APLP2-ICDs (a-c) or full-length APLP2751 (d) expressing HEK293 cells using anti-APLP2-ICDs (C12) (a, d) or anti-GFP antibodies (a-c). The purity of nuclear fractions was confirmed by Western blotting using anti$\beta$-tubulin antibody (a cytosolic marker) $(a, b)$ and anti-calnexin (an endoplasmic reticulum marker) $(a, d)$. The purity of the cytosolic fractions was confirmed by Western blotting with anti-histone-3 antibody (c). The protein level of $\beta$-tubulin and histone was examined as loading controls for cytosolic and nuclear fractions, respectively (b, c). (C) HEK293 cells were co-transfected with APLP2-ICDs in the pEGFP-N1 vector, and Fe65 in the pcDNA 3 flag vector. At 48-h post-transfection, immunocytochemical experiments were performed to investigate the colocalization of APLP2-ICDs with Fe65. Mock stands for the cells transfected with the pEGFP-N1 vector and Fe65 in the pcDNA3 flag vector. Photographs (a1-e1) show DAPI (1 $\mu \mathrm{M})$ staining indicating the location of the nucleus (blue), (a2-e2) show green fluorescence representing the location of APLP2-ICDs; (a3e3) indicate Cy3 fluorescence showing the location of Fe65 in the pcDNA 3 flag vector (red) by anti-flag antibody, conjugated by Cy3 labeled secondary antibody, and (a4-e4) indicate merged images. (D) HEK293 cells were co-transfected with full-length APLP2 751 in the pCB6 vector, and Fe65 in the pcDNA 3 flag vector, and then treated with DAPT or vehicle for 48-h after transfection. At $48 \mathrm{~h}$ post-transfection, immunocytochemical experiments were performed to investigate the subcellular localization of APLP2ICDs. Photographs (a1, b1) indicates DAPI (1 $\mu \mathrm{M})$ staining showing the location of the nucleus (blue), (a2, b2) indicates FITC fluorescence representing the location of APLP2 extracellular domains, (a3, b3) indicates Cy3 fluorescence showing the location of APLP2-ICDs (red), and (a4, b4) is merged images of each color 
laser scanning microscopy in HEK293 cells co-transfected with APLP2-ICDs (C57, C50, C57 ${ }^{\mathrm{Y738G}}$ or $\mathrm{C} 50^{\mathrm{Y738}}$ ) and Fe65. GFP and Сy3 fluorescence signals indicating APLP2 and Fe65 immunoreactivities, respectively, showed that APLP2ICDs (C57, C50) and Fe65 were colocalized mainly in the nucleus of the HEK293 cells and also in the cytoplasm
(Figure 1C (b1-b4 and d1-d4)), whereas the GFP signals corresponding to the empty vector or point mutated APLP2ICDs $\left(\mathrm{C} 57^{\mathrm{Y} 738 \mathrm{G}}, \mathrm{C} 50^{\mathrm{Y} 738}\right)$ were observed evenly throughout the cytoplasm and nucleus (Figure 1C (a1-a4, c1-c4 and e1-e4)). Higher level of Fe65 immunoreactivity in the cytoplasm of cells expressing mock or Y738G mutated
C

a1

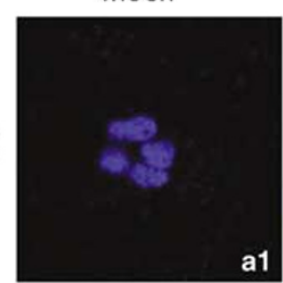

a2

Fe65-flag

APLP2-ICDsGFP

a3

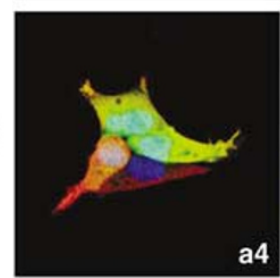

C57

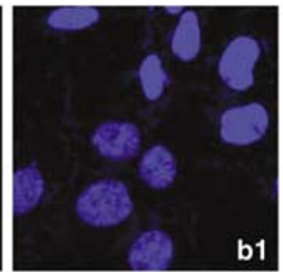

C57 $7^{\mathrm{Y} 38 \mathrm{G}}$

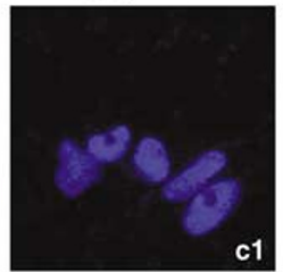

C50

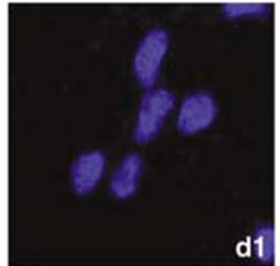

d1
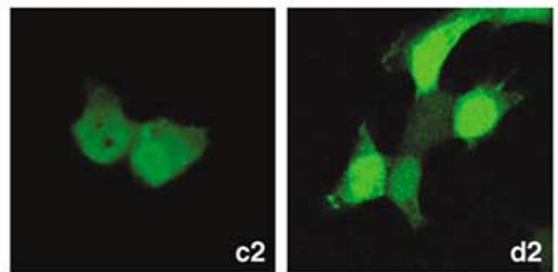

e1
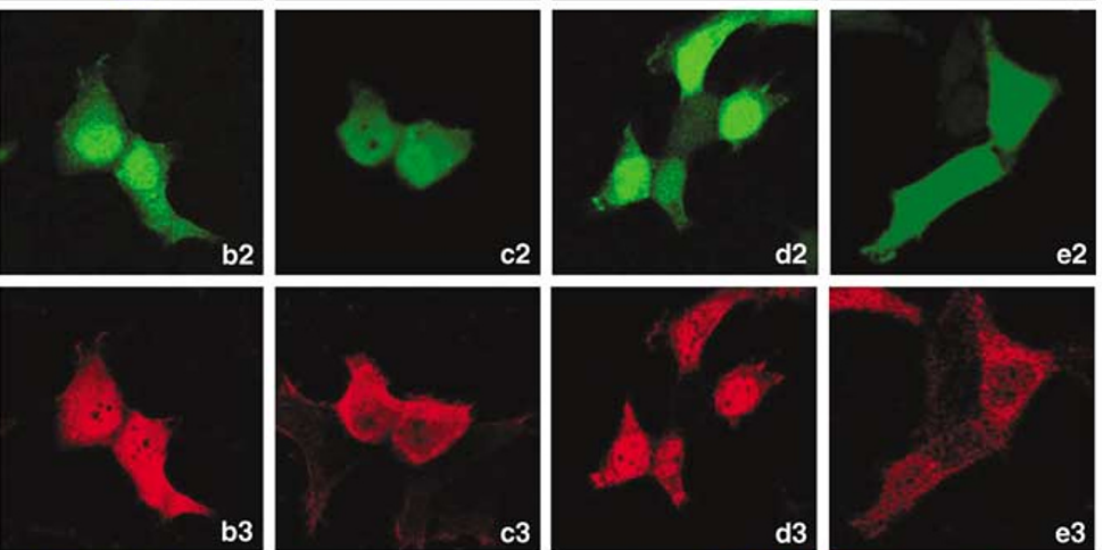

d3
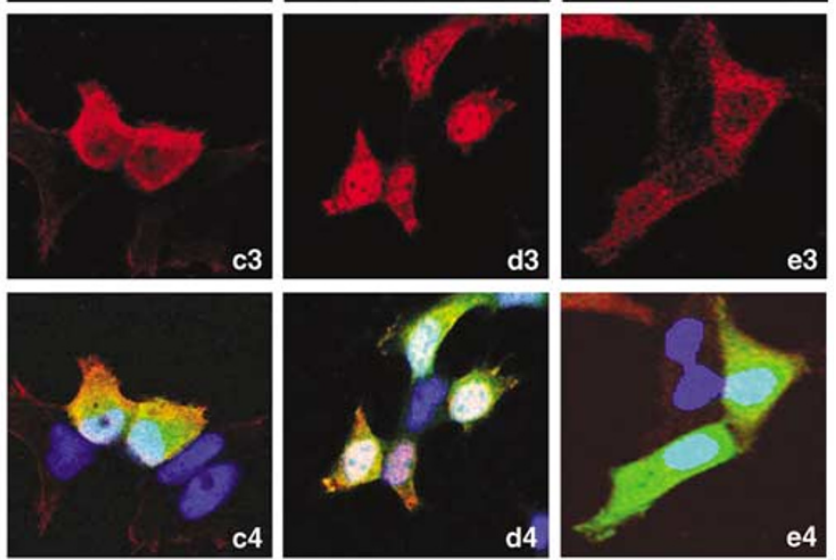

merged

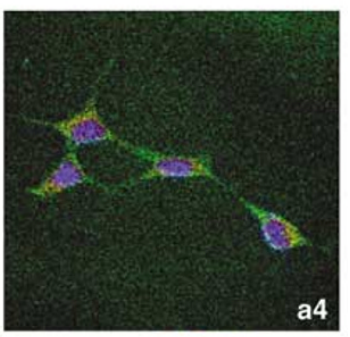

a2
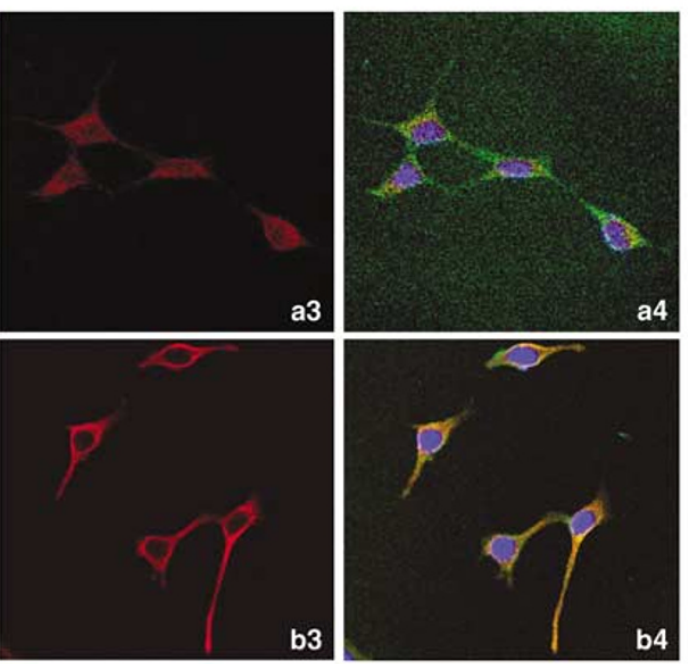

Figure 1 (Continued) 
APLP2-ICDs led us to hypothesize that the nuclear localization of Fe65 is also dependent on APLP2-ICDs (Figure 1C (a1-a4, $c 1-c 4$ and e1-e4)), consistent with other previous report. ${ }^{10}$
The C57 or C50-GFP fusion proteins have an approximately $31 \mathrm{kDa}$ molecular weight, which is below the exclusion limit of size to pass the nuclear membrane by passive
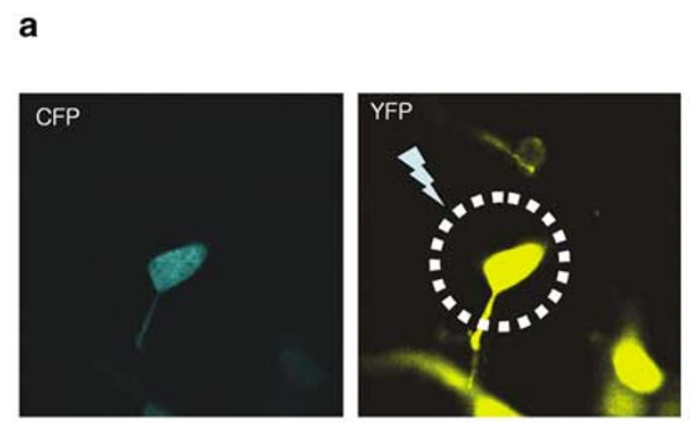

Before Photobleaching

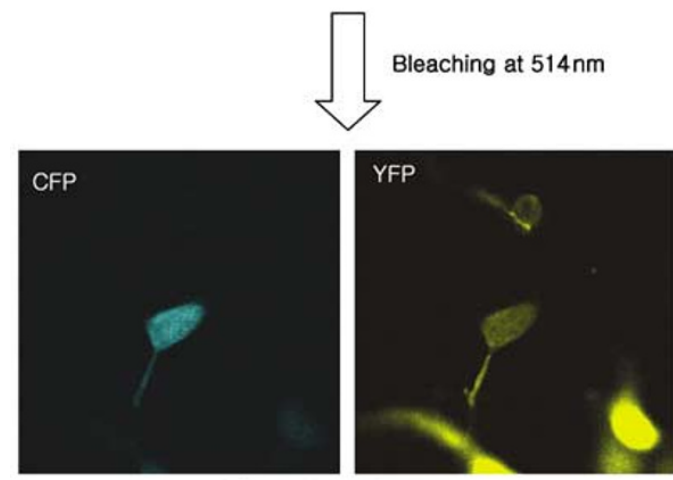

After Photobleaching

b
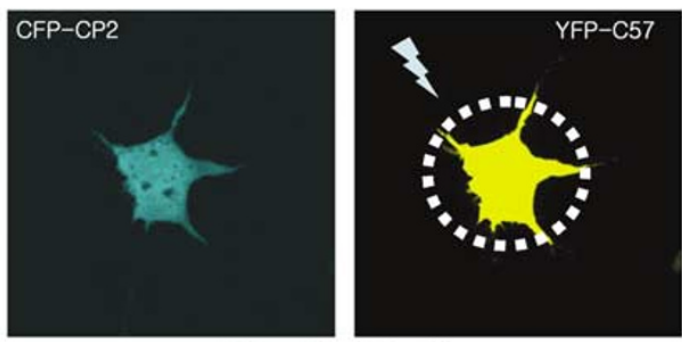

Before Photobleaching
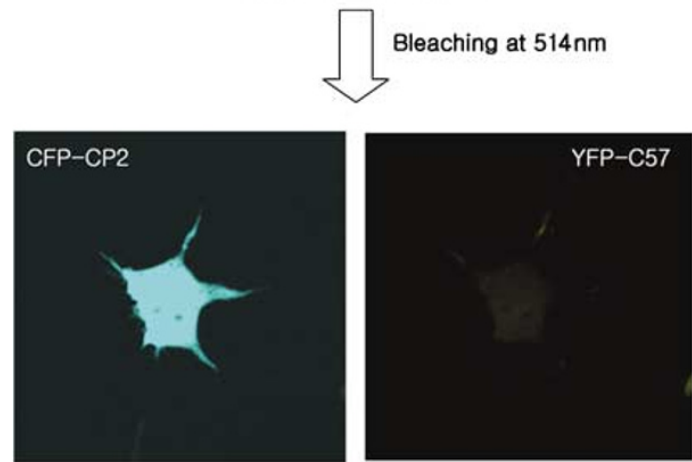

After Photobleaching
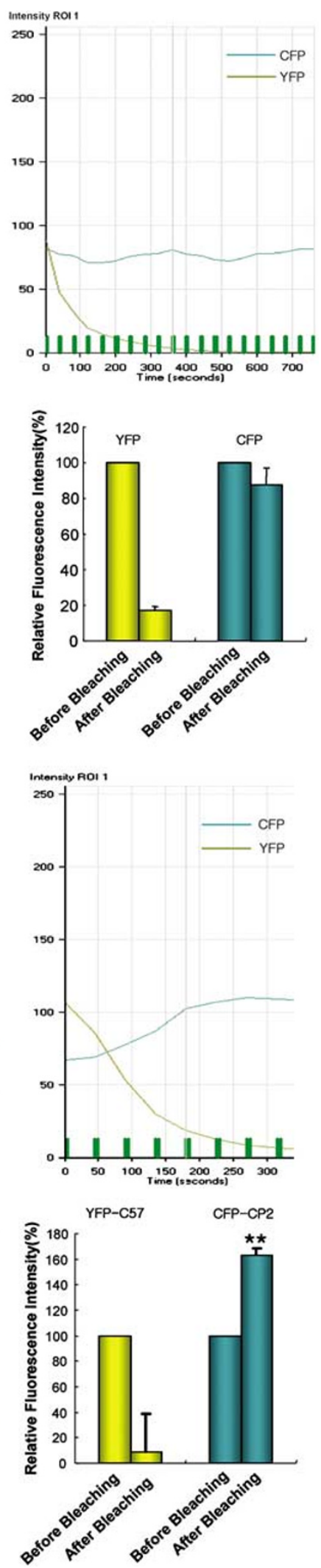

Figure 2 (Continued) 
diffusion. To investigate whether APLP2-ICDs could translocate into the nucleus by an active transport system, we generated construct encoding fusion protein composed by two consecutive GFP units fused to C57 (Figure 1A). As shown in Supplementary Figure S1a, GFP-GFP fusion protein is mostly found in the cytoplasm, as expected from its molecular size, whereas the C57-GFP-GFP is observed mainly in the nucleus despite of its large molecular size (Supplementary Figure S1b).
In Figure 1D, HEK293 cells were co-transfected with fulllength APLP2-751 in the pCB6 vector and Fe65 in the pcDNA3 flag vector. The transfected cells were incubated in the presence or in the absence of DAPT $\{N-[N-(3,5-$ difluorophenacetyl)-L-alanyl]-S-phenylglycine $t$-butyl ester\}, an inhibitor of $\gamma$-secretase, at $2 \mu \mathrm{M}$ for $48 \mathrm{~h}$, and then labeled with $\mathrm{C} 12$ antibody and APLP2 (C17) antibody, which specifically recognizes the APLP2 N-terminal extracellular domain, conjugated with Сy3 or FITC, respectively.
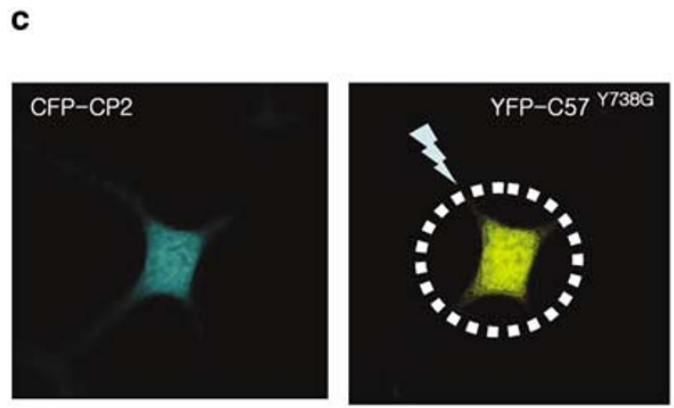

Before Photobleaching
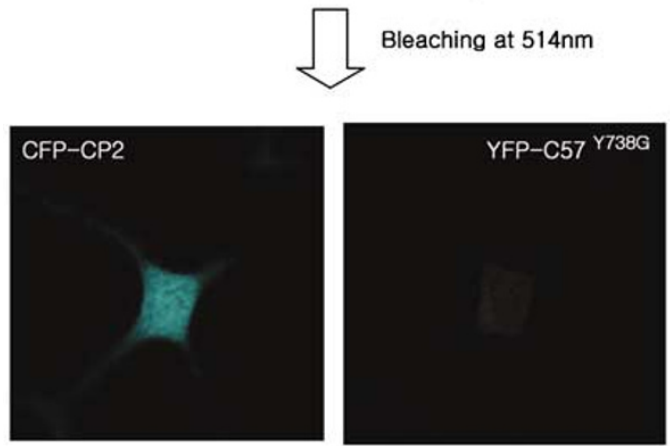

After Photobleaching

d

IP: anti-APLP2-C12 antibody
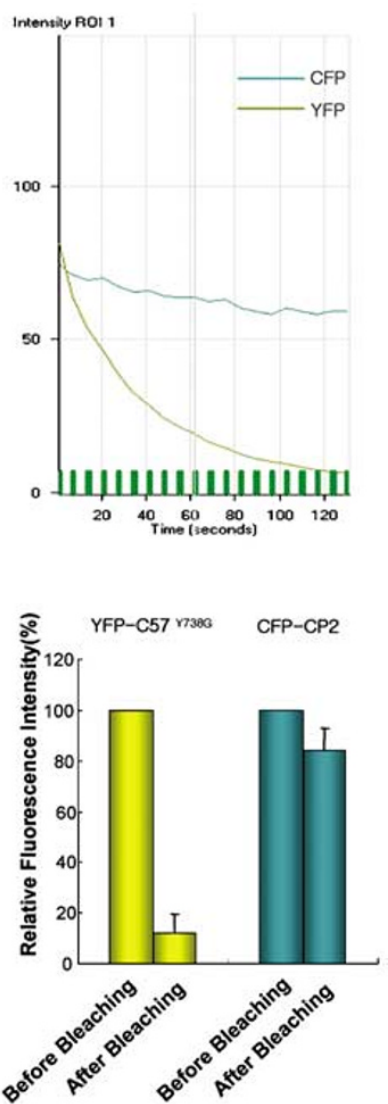

IB: anti -CP2 anti serum

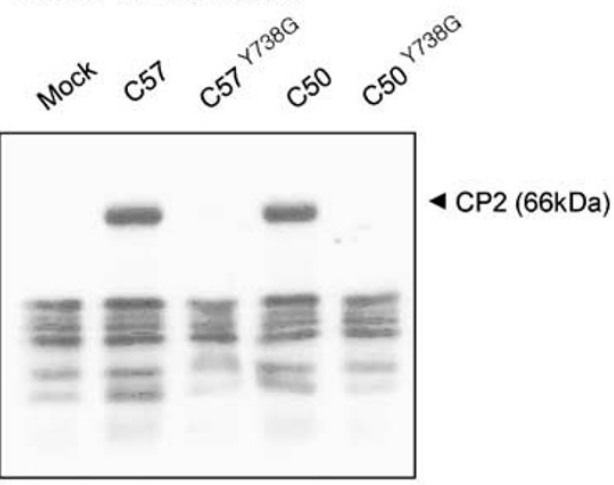

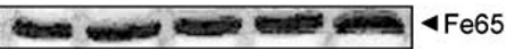

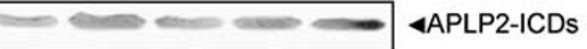


Vehicle-treated cells showed APLP2-CTFs immunoreactivity in the nucleus (Figure 1D (a1, a3 and a4)). By contrast, the APLP2-CTFs immunoreactivity represented by Cy3 fluorescence was not observed in the nucleus of the cells treated with DAPT (Figure 1D (b1, b3 and b4)). The FITC fluorescence representing the presence of APLP2 N-terminal extracellular domain was not observed in the nucleus in the presence or absence of DAPT treatment (Figure 1D (a1, a2, a4, b1, b2 and b4)).

\begin{abstract}
Molecular interaction between C57 and CP2 transcription factor by fluorescence resonance energy transfer (FRET) analysis. Fe65 is reported to interact with CP2 transcription factor through its PTB1 domain. ${ }^{19}$ Here, we examined whether C57 interacts with CP2 transcription factor by employing an FRET method (Figure 2(a-c)). HEK293 cells on coverslips in six-well plates were transiently co-transfected with one of the following combinations: (1) pEYFP vector and pECFP vector, (2) YFP-C57 and CFP-CP2, (3) YFP-C57 ${ }^{\text {Y738G }}$ and CFP-CP2. At $24 \mathrm{~h}$ after transfection, the coverslips were mounted on Axiovert 200 inverted microscope (Zeiss, Jena Germany). The energy transfer was detected as an increase in donor fluorescence (ECFP) after complete photobleaching of the acceptor molecules (EYFP). Cells showing both of ECFP and EYFP signals were photobleached at $514 \mathrm{~nm}$ (laser power $100 \%$ ) to destroy the acceptor molecules. The cells were rescanned using 458-nm light and an increase of the ECFP signal within the photobleached area was used as a measure of FRET. As shown in Figure 2a, in the cells co-expressing pECFP and pEYFP vectors only, CFP donor signal was rather slightly decreased to $87.8 \pm 3.1 \%$, after photobleaching of YFP signal at $514 \mathrm{~nm}$. In Figure $2 \mathrm{~b}$, CFP donor signal was significantly increased to $163.3 \pm 13.2 \%$ $(P<0.01, n=7)$, after complete photobleaching of YFP signal at $514 \mathrm{~nm}$, indicating that FRET is present between CFP-CP2 and YFP-C57. By contrast, FRET was not observed between YFP-APLP2-C57 $7^{\text {Y738G }}$ and CFP-CP2, suggesting that YENPTY, an Fe65 interacting domain is critically required for the interaction between C57 and CP2 transcription factor (Figure 2c). HEK293 cells are expressing endogenous Fe65, so it remains to be determined whether C57 and CP2 interact directly or indirectly through Fe65.

We confirmed these results by using an immunoprecipitation method (Figure 2d). APLP2-ICDs tagged with a GFP
\end{abstract}

sequence and Flag-tagged Fe65 were transiently co-expressed in HEK293 cells, and it was confirmed that all transfected proteins were equally expressed in all the groups (Figure 2d). The immunoprecipitation of APLP2-ICDs by $\mathrm{C} 12$ antibody and immunoblotting for CP2 demonstrated that the transfected APLP2-ICDs (C57, C50) and endogenously existing CP2 interacted in the nuclear fraction (Figure 2d), whereas the Y738G point mutated APLP2-ICDs (C57 ${ }^{\text {Y738G, }}$ C50 ${ }^{\mathrm{Y738G}}$ ) did not (Figure 2d). Our findings demonstrate that the APLP2-ICDs and CP2 interact in the nucleus and that interactions between these proteins are governed by YENPTY domain in APLP2-ICDs.

APLP2-ICDs induce GSK-3 $\beta$ expression, and $\tau$ phosphorylation in NGF-differentiated PC12 cells and rat primary cortical neurons whereas the Y738G point mutants do not. Based on the finding that APLP2-ICDs and CP2 transcription factor interact in the nucleus, we examined changes in GSK-3 $\beta$, one of the genes regulated by CP2 transcription factor. GSK-3 $\beta$ protein was upregulated in C57- or C50 expressing HEK293, NGF-differentiated PC12 cells and in rat primary cortical neurons, but not in cells expressing $\mathrm{C} 57^{\mathrm{Y738G}}, \mathrm{C} 50^{\mathrm{Y738G}}$ (Figure 3a). We also checked for changes in $\mathrm{Tyr}^{216}$ phosphorylated GSK-3 $\beta$, an active form of this enzyme. Phosphorylated GSK-3 $\beta$ at Tyr ${ }^{216}$ was increased in C57 or C50 expressing NGF-differentiated PC12 cells, but was not increased in the Y738G point mutated APLP2-ICDs (C57 ${ }^{\text {Y738G }}$, C50 ${ }^{\text {Y738G }}$ ) transfected cells (Figure 3a). It has been reported that the activity of GSK-3 $\beta$ is mediated by the phosphorylation of two distinct sites, and by transcriptional regulation. ${ }^{20} \mathrm{Tyr}^{216}$ phosphorylation, which is necessary for its activity, is known to increase in response to apoptotic stimuli in neuronal cells. ${ }^{21}$ The GFP tagged APLP2-ICDs were confirmed to be equally expressed in mock, APLP2-ICDs and Y738G mutated APLP2-ICDs transfected cells, by using anti-GFP antibody (data not shown).

The mRNA level of GSK-3 $\beta$ was also increased in APLP2ICDs transfected PC12 cells (Figure $3 b$ ). However, forms containing the $Y 738 \mathrm{G}$ point mutation in the ${ }^{738} \mathrm{YENPTY}^{743}$ domain of APLP2-ICDs (C57 ${ }^{\text {Y738G }}, \mathrm{C} 50^{\text {Y738G }}$ ) did not upregulate the GSK-3 $\beta$ at either the protein or mRNA level in PC12 cells, indicating that YENPTY, an Fe65 interacting domain is critical for the induction of GSK-3 $\beta$ expression (Figure 3 (a and b)).

Figure 2 Molecular interaction between APLP2-C57 and CP2 transcription factor examined by FRET. HEK293 cells on coverlips in six well plates were transiently cotransfected with one of the following combinations: (a) pEYFP vector and pECFP vector, (b) YFP-C57 and CFP-CP2, (c) YFP-C57 ${ }^{\text {Y738G }}$ and CFP-CP2. At 24 h after cotransfection, the coverslips were mounted on Axiovert 200 inverted microscope (Zeiss, Jena Germany). An initial scan was obtained at low energy using the 458 line of the argon laser to record the ECFP signal. A second scan was performed with the 568 line, and cells of colocalization was noted. Cells were then photobleached with intense $514 \mathrm{~nm}$ light (laser power 100\%) to destroy the acceptor molecules, EYFP. The energy transfer was detected as an increase in donor fluorescence (ECFP) after complete photobleaching of the acceptor molecules (EYFP) at $514 \mathrm{~nm}$. The amount of energy transfer was calculated as the percent increase in donor fluorescence after acceptor photobleaching. An increase of the ECFP signal within the photobleached area was used as a measure of the amount of FRET present. Figures in the left panel show representative results from the seven independent experiments. The right upper panel shows a representative graph indicating the time-lapse fluorescence changes in the region of interest (ROI). The green line represents the ECFP fluorescence; gray, EYFP throughout the progression of successive bleaching marked as vertical green bars. In the right lower panel, relative fluorescence intensity is denoted after standardization of intensities before and after photobleacing of EYFP at $514 \mathrm{~nm}$. ${ }^{\star} P<0.05$ versus fluorescence intensity before photobleaching of YFP at $514 \mathrm{~nm}$ (by one-way ANOVA). To confirm the interactions between APLP2-ICDs and CP2, we performed immunoprecipitation and immunoblotting. (d) First, samples obtained from the nuclear fraction of HEK293 cells transfected with APLP2-ICDs in pEGFP-N1 were immunoprecipitated with anti-APLP2 (C12) antibody, immunoblotting with anti-CP2 antiserum. The expression levels of APLP2-ICDs in pEGFP-N1 in HEK293 cells, were checked using anti-GFP antibody 
To investigate whether endogenously generated APLP2ICDs affect GSK-3 $\beta$ expression, we examined the effect of DAPT on GSK-3 $\beta$ levels after transfecting full-length APLP2 into HEK293 cells and found that the GSK-3 $\beta$ was not upregulated in the DAPT treated cells, indicating that the ICDs

a
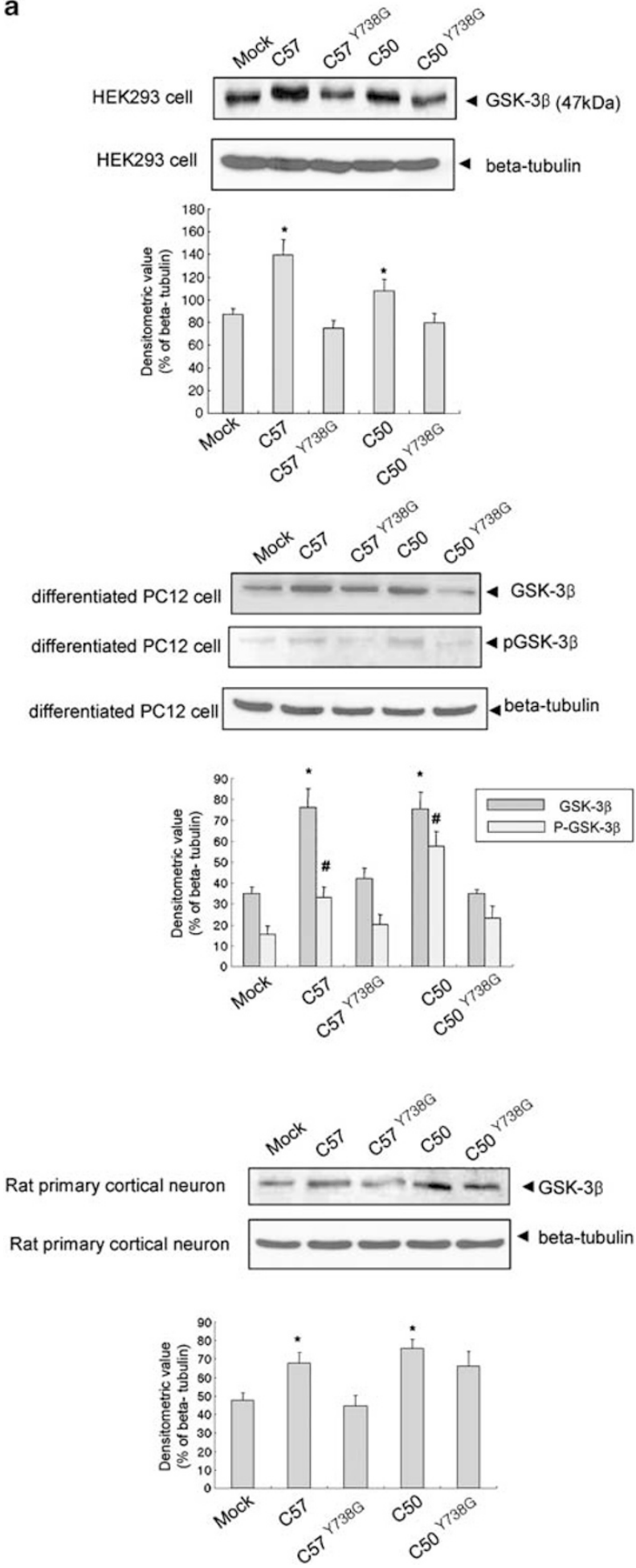

generation by $\gamma$-secretase activity is critical for GSK-3 $\beta$ expression (Figure 3c). We confirmed a significant decrease in ICD production by DAPT treatment both in the nuclear fraction and in whole-cell lysates of HEK293 cells overexpressing full-length APLP2 (data not shown). b
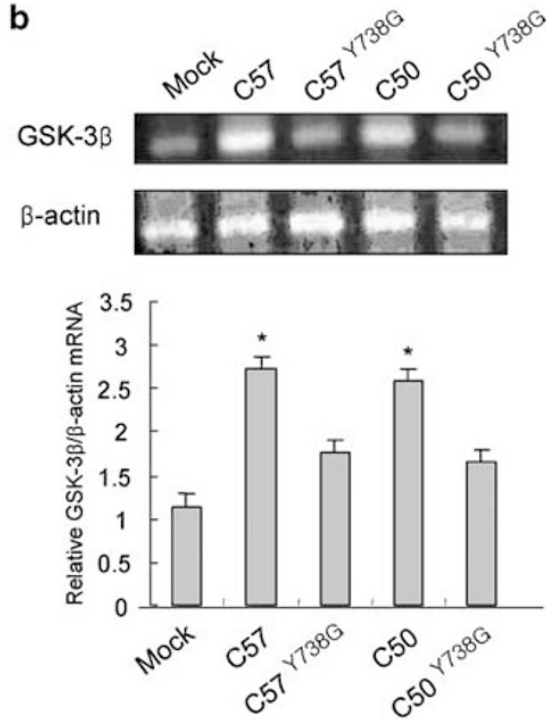

c
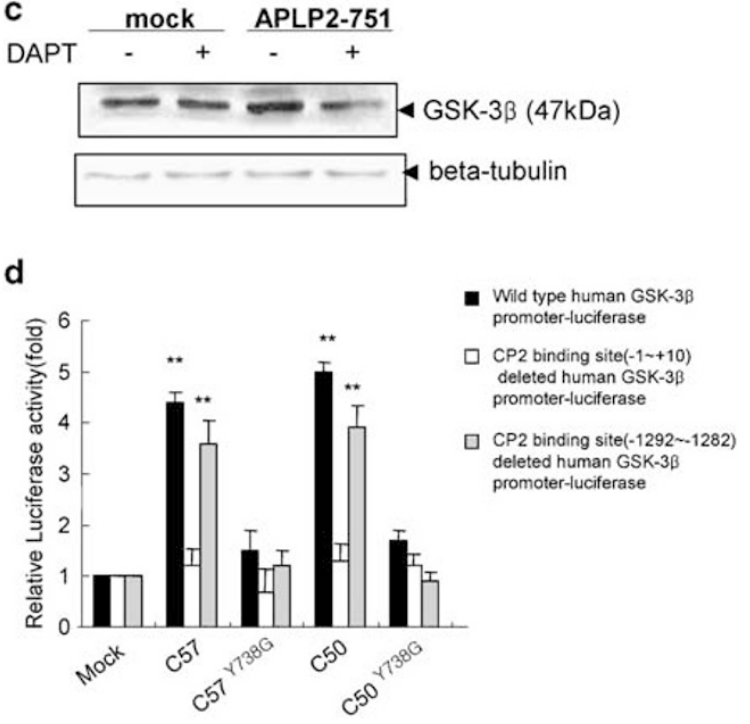

Figure 3 (Continued) 

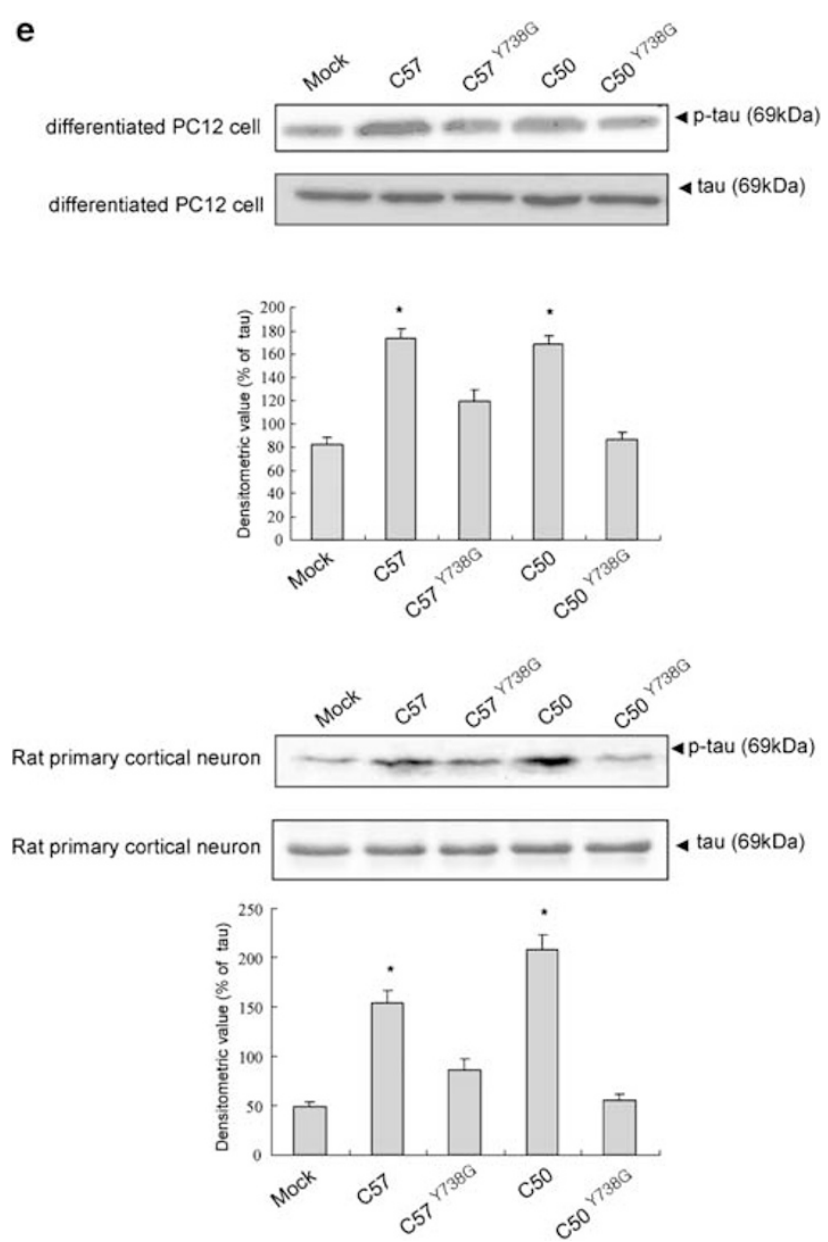

Figure 3 APLP2-ICDs induce GSK-3 $\beta$ expression, and upregulate its promoter activity and $\tau$ phosphorylation in NGF-differentiated PC12 cells, rat primary cortical neurons and HEK293 cells. (a) At 48-h post-transfection, the changes in GSK-3 $\beta$ protein and p-GSK-3 $\beta$ at Tyr ${ }^{216}$ were checked by Western blotting with anti-GSK-3 $\beta$ or anti-p-GSK-3 $\beta$ at Tyr ${ }^{216}$ antibodies in HEK293 cells, PC12 cells and rat primary cortical neurons transfected with APLP2-ICDs. The graph shows the densitometric value of the GSK- $3 \beta$ or $p$-GSK- $3 \beta$ versus $\beta$-tubulin ( ${ }^{*}$ GSK- $3 \beta$ ), ${ }^{\#} P<0.05$ (p-GSK$3 \beta$ ) by one-way ANOVA). (b) At 48-h post-transfection, GSK-3 $\beta$ mRNA levels were determined by RT-PCR in PC12 cells transfected with APLP2-ICDs. The relative ratios of the levels of GSK-3 $\beta$ and $\beta$-actin mRNA were normalized using the M4 image analysis program $\left({ }^{*} P<0.05\right.$, by one-way ANOVA). (c) At 48 -h posttransfection, GSK-3 $\beta$ levels were examined in HEK293 cells expressing full-length APLP2, which had been incubated in the presence or absence of DAPT, a $\gamma$ secretase inhibitor. (d) GSK-3 $\beta$ promoter activity was measured by luciferase activity assay in PC12 cells cotransfected with APLP2-ICDs and wild-type human GSK-3 $\beta$ promoter or deletion mutants of human GSK-3 $\beta$ promoter without $n$ -1292 to $\sim 1282$ or $n t-1$ to $\sim+10$ in the $\mathrm{pGL2}$ vector. Data represent the means \pm S.E. of four separate experiments. ${ }^{\star *} P<0.01$ by one-way ANOVA). (e) Changes in phosphorylated tau at the $\mathrm{Ser}^{202}$ and $\mathrm{Thr}^{205}$ residues were checked using AT8 antibody in PC12 cells and rat primary neurons expressing APLP2-ICDs. The graph shows the densitometric value of $P$-tau versus tau ( ${ }^{\star} P<0.05$ by one-way ANOVA)

In order to confirm the effects of APLP2-ICDs on GSK-3 $\beta$ induction, GSK-3 $\beta$ promoter activity was measured by luciferase activity assay after co-transfecting APLP2-ICDs and human GSK-3 $\beta$ promoter in the pGL2 vector. GSK-3 $\beta$ promoter activity was significantly increased by about four- to five-fold in PC12 cells expressing C57 or C50. No significant increase was observed in the cells expressing APLP2-ICDs containing a $Y 738 G$ point mutation (Figure 3d).

GSK-3 $\beta$ promoter has potential c-Myb, CRE, AP1, AP2, Tst-1, Sp1 and MZF-1 binding sites in addition to two CP2 binding sites. Putative CP2 binding sites were identified at $\mathrm{nt}$ -1292 to $\sim-1282$ and $n t-1$ to $\sim 10$ by Lau et al., ${ }^{20}$ and it has been reported that very low reporter gene expression is found when the region between $\mathrm{nt}-171$ and +29 was deleted, indicating that essential elements had been removed. In our study, we prepared deletion mutants without nt -1292 to -1282 (GCGCACACCAA) or $\mathrm{nt}-1$ to $\sim+10$ (GCCCGGGCCAA). Promoter activity was determined by luciferase assay after co-transfecting APLP2-ICDs (C57, $\mathrm{C} 50, \mathrm{C} 57^{\mathrm{Y} 738 \mathrm{G}}$ and $\mathrm{C} 50^{\mathrm{Y} 738 \mathrm{G}}$ ) with one of these deletion mutants of human GSK-3 $\beta$ promoter in the pGL2 vector. As shown in Figure $3 \mathrm{~d}$, deletion of the CP2 binding site nt -1 to $\sim+10$ inhibited the promoter activity upregulation by APLP2ICDs (C57, C50), whereas deletion of CP2 binding site nt -1292 to $\sim-1282$ did not affect the upregulation of the human GSK-3 $\beta$ promoter activity by APLP2-ICDs (C57, C50). Our results show that $C P 2$ binding site located at the $n t-1$ to $\sim+10$ sequence in the human GSK-3 $\beta$ promoter region are essential for the gene transcription by APLP2-ICDs.

$\tau$, whose hyperphosphorylated form is a main component of neurofibrillary tangles (NFTs), is a substrate of GSK-3 $\beta{ }^{22,23}$ At $48 \mathrm{~h}$ post-transfection, we checked the phosphorylation level of $\tau$, at its $\mathrm{Ser}^{202}$ and $\mathrm{Thr}^{205}$ residues by Western blotting in APLP2 ICDs-transfected PC12 cells and in rat primary neurons using AT8 antibody. In APLP2 ICDs-transfected cells, the level of $\tau$ phosphorylation at $\mathrm{Ser}^{202}$ and $\mathrm{Th}^{205}$ residues was found to be significantly increased without changes in nonphosphorylated form of $\tau$. However, no significant increase in $\tau$ phosphorylation was found for Y738G mutated APLP2 ICDs-transfected groups (Figure 3e).

The overexpression of APLP2-ICDs decreases cell viabilities in NGF-differentiated PC12 cells, and in HEK293 cells. We evaluated the viabilities of C57, C50,

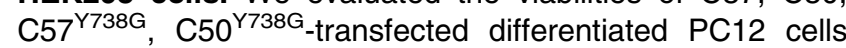
(Figure 4a) and HEK293 cells (Figure 4b) by an LDH release assay. At 48-h post-transfection, cells expressing C57 or C50 showed increased LDH release by about $30 \%$ (versus the nontransfected controls), while cells expressing Y738G

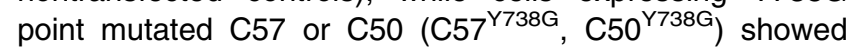
significantly lower LDH release than those expressing C57 or C50 (Figure $4(a$ and $b)$ ), indicating that YENPTY, an Fe65 binding domain contributes to cellular toxicity.

To examine whether GSK-3 $\beta$ is responsible for the reduced cell viability by $\mathrm{C} 57$ or $\mathrm{C} 50$, we checked the effects of two GSK-3 $\beta$ inhibitors. $\mathrm{LiCl}$ and indirubin-3'-monoxime, 5-iodo were treated for $48 \mathrm{~h}$ post-transfection at $10 \mathrm{mM}$ and at $9 \mathrm{nM}$, respectively, and the cell viabilities were evaluated NGF-differentiated PC12 and HEK293 cells overexpressing APLP2-ICDs. These treatments significantly prevented cellular death induced by APLP2-ICDs (Figure 4 (a and c)), indicating that the GSK-3 $\beta$ induction by APLP2-ICDs is related to the reduced cell viability. Next, we investigated whether APLP2-ICDs induced apoptosis in HEK293 cells using Hoechst 33258 dye staining. The cells transfected with C57 or C50 showed significant nuclear condensation as 

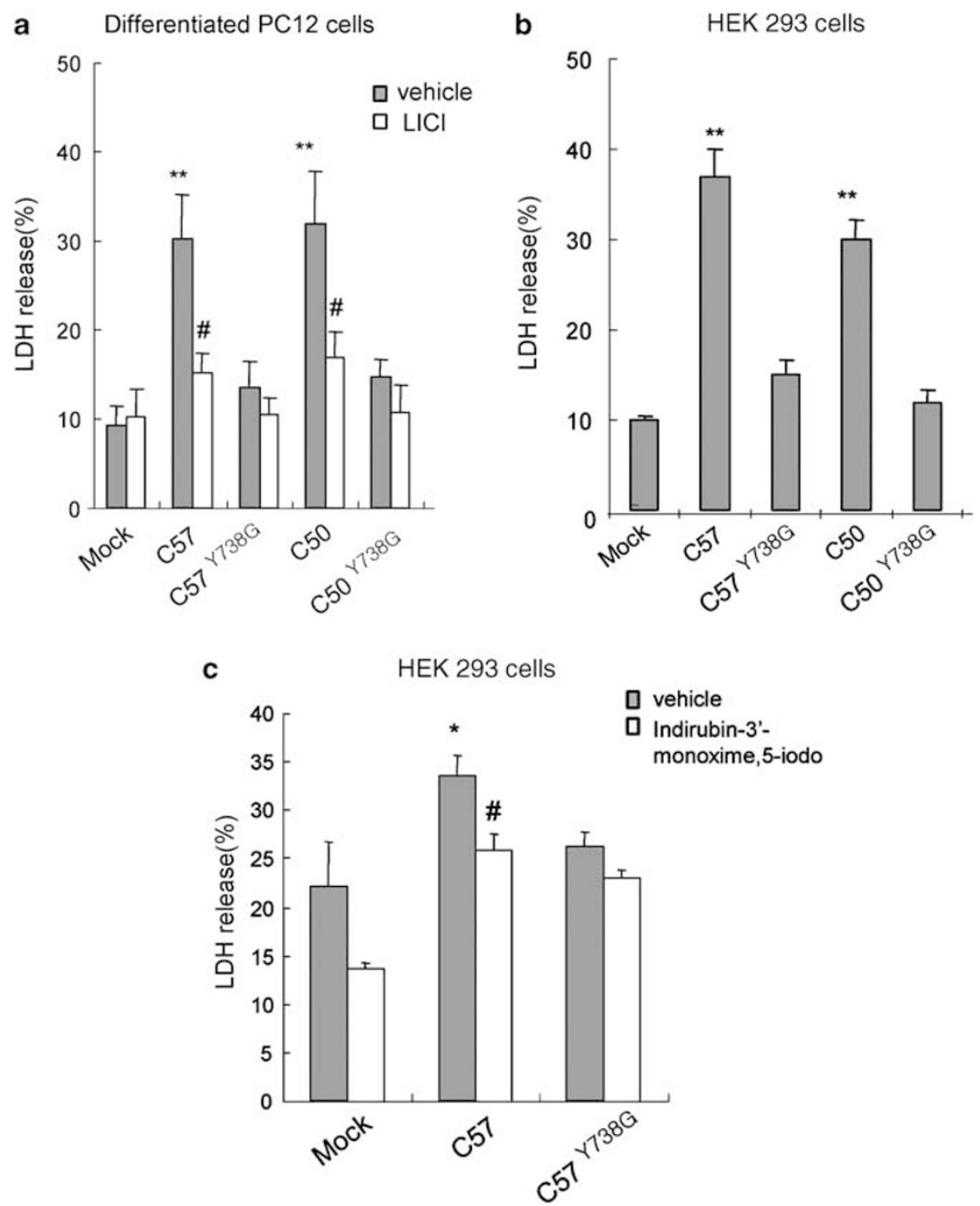

Figure 4 APLP2-ICDs decrease cell viabilities in NGF-differentiated PC12 cells, and in HEK293 cells. (a) Cell viabilities after treatment with LiCl (10 mM) were measured by a LDH assay in PC12 cells expressing APLP2-ICDs. Data represent the means \pm S.E.M. of four separate experiments. ${ }^{* *} P<0.01$ versus mock transfected cells, ${ }^{\#} P<0.05$ versus vehicle treated APLP2-ICDs transfected cells, by one-way ANOVA). (b) The cell viabilities of mock, C57-, C50 or Y738G point mutated APLP2-ICDs (C57 $7^{\text {Y738G }}$, ${ }^{C} 50^{\text {Y738G }}$-transfected HEK293 cells were assessed by an LDH assay $\left({ }^{* *} P<0.01,{ }^{*} P<0.05\right.$, by one-way ANOVA). (c) Cell viabilities after treatment with indirubin-3'monoxime, $5^{\prime}$ iodo $(9 \mathrm{nM})$, were measured by an LDH assay in PC12 cells expressing APLP2-ICDs. Data represent the means + S.E.M. of four separate experiments $\left({ }^{\star} P<0.01\right.$ versus mock transfected cells, ${ }^{\#} P<0.05$ versus vehicle treated APLP2-ICDs transfected cells, by one-way ANOVA). (d) HEK293 expressing mock or APLP2-ICDs were stained with Hoechst 33258 dye

shown in Supplementary Figure S2; this finding is consistent with the report that conditional GSK-3 $\beta$ transgenic mice show TUNEL positive and cleaved caspase-3 immunostained neurons. ${ }^{24}$

Immunoreacitivities for APLP2-CTFs and GSK-3 $\beta$ are elevated in the AD brain. The localization of APLP2-CTFs and GSK-3 $\beta$ in a total of five AD and four nondemented age-matched control cases was examined. Immunostaining of APLP2-CTFs using C12 antibody showed that the cytoplasmic and the nuclear immunoreactivities of APLP2CTFs are present in the neurons of hippocampus, dentate gyrus and parahippocampal cortex of the human $A D$ brain
(Braak stage $\mathrm{V},{ }^{25}$ ) (Figure 5A (a, c, e, g and i)). Especially, nuclear immunoreactivities for APLP2-CTFs in CA1, 2, 3 and parahippocampal cortex were significantly stronger than the same regions of age-matched control brains (Figure 5A (a, c, e and i)). However, the APLP2-CTFs immunoreactivities in dentate gyrus were not significantly different from the agematched control brains (Figure 5A ( $g$ and $h)$ ).

The GSK-3 $\beta$ immunoreactivity was greatly increased in the neurons of the hippocampus (Figure 5B (a and $c)$ ), in the neurons of the dentate gyrus (Figure 5B (e)), and in the parahippocampal cortex (Figure $5 B(\mathrm{~g})$ ) of the $A D$ brains versus the normal age-matched control brains (Figure $5 \mathrm{~B}$ (b and d) (hippocampal neurons), $f$ (dentate gyrus) and $h$ (parahippocampal cortex)). 
A

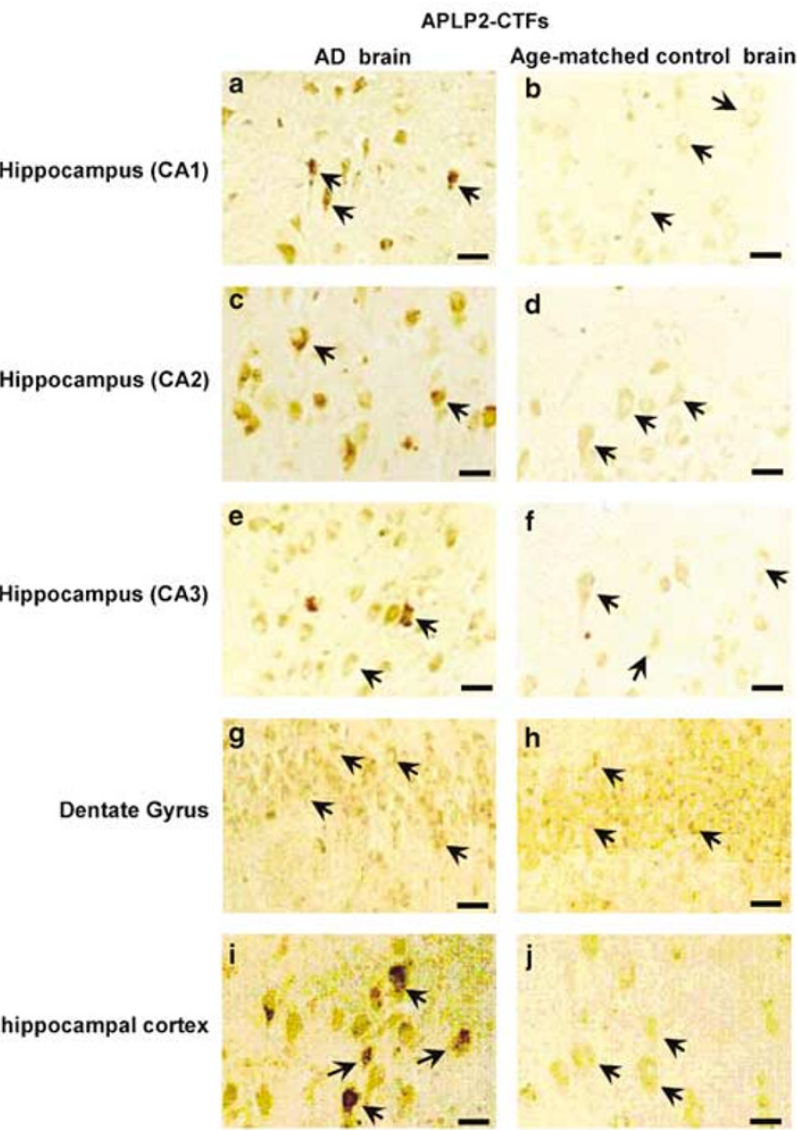

B

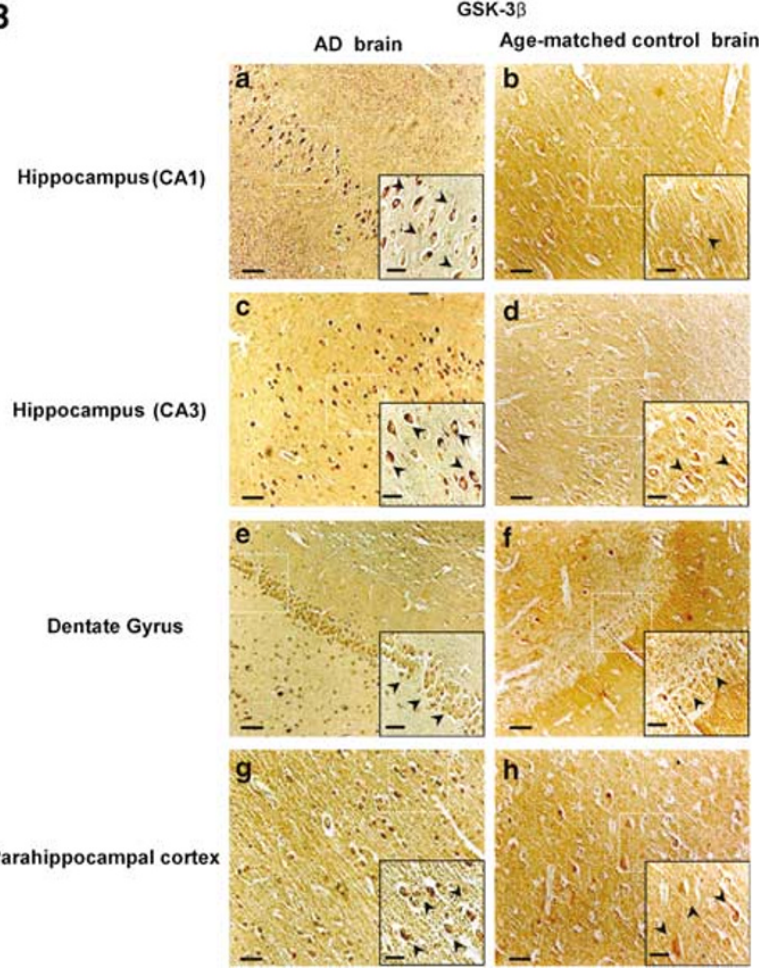

Figure 5 APLP2-CTFs and GSK-3 $\beta$ immunoreactivities are elevated in the AD brain. The immunoreactivities of APLP2-CTFs (A) and GSK-3 $\beta$ (B) were examined in the hippocampus $(\mathbf{A}(\mathrm{a}, \mathrm{c}, \mathrm{e}) ; \mathbf{B}(\mathrm{a}, \mathrm{c}))$, the dentate gyrus $(\mathbf{A}(\mathrm{g}), \mathbf{B}(\mathrm{e}))$, and in the parahippocampal cortex $(\mathbf{A}(\mathrm{i}), \mathbf{B}(\mathrm{g}))$ of $\mathrm{AD}$ brain and normal age-matched control brain (hippocampus, $\mathbf{A}(b, d, f), \mathbf{B}(b, d)$; dentate gyrus, $\mathbf{A}(\mathrm{h}), \mathbf{B}(\mathrm{f})$; parahippocampal cortex, $\mathbf{A}(\mathrm{j}), \mathbf{B}(\mathrm{h})$ ) using $\mathbf{C} 12$ antibody which specifically recognizes the last 12 amino acids of APLP2, and anti-GSK-3 $\beta$ antibody, respectively. Scale bar in (A) indicates $50 \mu \mathrm{m}$, in (B); lower magnification photographs $(\times 100)$ indicates $100 \mu \mathrm{m}$; in inset $(\times 400), 50 \mu \mathrm{m}$. Arrowheads indicate APLP2-CTFs and GSK-3 $\beta$, in the cytoplasm; the arrow indicates APLP2-CTFs in the nucleus

\section{Discussion}

In the present study, we examined the pathophysiological roles for APLP2-ICDs (C57, C50), generated by $\gamma$ - or $\varepsilon$ - secretases in $A D$ pathogenesis. Among the three members of the APP gene family, the pathophysiological significance of APLP1 and APLP2 in relation to AD has not been adequately investigated until recently. 
APP has been shown to undergo extensive proteolytic processing by two major pathways. ${ }^{26,27}$ APP, which is a type I transmembrane protein as well as APLPs, is cleaved consecutively, first at the extracellular juxtamembrane region by $\alpha$ - or $\beta$-secretase and secondly at the intramembrane region by $\gamma$-secretase. ${ }^{26}$

Similarly with APP, the N-terminal ectodomain of APLP2 is shedded by $\beta$-secretase ${ }^{28,29}$ as well as by ADAM 10 and $17,{ }^{30}$ whereas the $\mathrm{C}$-termini remain in the membrane ${ }^{10,28}$ and can be further processed by $\gamma$-or $\varepsilon$-secretase ${ }^{13,14}$ to release ICDs with signaling properties. ${ }^{10,28}$

The APLP2-ICDs are known to interact with Fe65 via a YENPTY domain, which APP, APLP1 and APLP2 have in common in their $\mathrm{C}$-terminus, translocating into the nucleus by Fe65-dependent manner ${ }^{8}$ and show Fe65-dependent gene transcriptional activity by heterologous reporter genes. ${ }^{10}$ Neprilysin gene transcription is reported to be upregulated by APLP-ICDs as well as the ICDs of APP and APLP1. ${ }^{31}$

In the present study, based on the previous report that the Fe65 PTB1 domain interacts with the CP2 transcription factor, ${ }^{19}$ we reasoned that APLP2-ICDs might interact with the CP2 transcription factor in the nucleus. Therefore, we investigated the interaction of APLP2-ICDs with CP2. APLP2ICD was found to interact with the CP2 transcription factor in the nucleus by employing FRET and immunoprecipitation methods.

CP2 is the prototypical member of a novel mammalian protein family sharing a high degree similarity to Elf-1, a Drosophila melanogaster tissue-specific factor. ${ }^{32}$ By interacting with a hyphenated sequence composed of two directly repeated four base pair motifs repeated by a 6-bp linker (CNRG-N6-CNR [G/C]), a ubiquitously expressed CP2 transcription factor regulates some genes including GSK-3 $\beta$, $\alpha$-macroglobulin and certain factors involved in the inflammatory response that exert T-cell responses when subjected to mitogenic stimulation. ${ }^{20,32}$ A previous report showed that the A allele of the $3^{\prime}$-UTR CP2 gene polymorphism has been reported to increase the risk of sporadic $A D{ }^{33}$

We examined the effects of APLP2-ICDs on the expression of GSK-3 $\beta$, a gene known to be regulated by the CP2 transcription factor. The APLP2-ICDs increased both GSK-3 $\beta$ protein and mRNA levels in HEK293, NGF-differentiated $\mathrm{PC} 12$ cells and in rat primary cortical neurons. By contrast, the Y738G point mutated APLP2-ICDs did not affect GSK-3 $\beta$ expression, indicating that the interaction of ICDs with Fe65 via the YENPTY domain in the C-terminus of APLP2 is essential for the gene-inducing effects of APLP2-ICDs.

GSK-3 $\beta$ is an important regulator of several cellular processes, which include transcription, cell cycle progression, cell survival and cytoskeletal organization. ${ }^{34-37}$ Increased levels of GSK- $3 \beta$ have been found in the AD brain, and active GSK-3 $\beta$ was found to accumulate in pretangle neurons. ${ }^{38}$ Transgenic mice overexpressing GSK-3 $\beta$ were shown to display $\tau$ hyperphosphorylation, disrupted microtubules, and apoptotic neurons. ${ }^{24}$ These results imply that alterations in the control of GSK-3 $\beta$ expression may occur in the AD brain. Our results also show that immunoreactivities for the nuclear APLP2-CTFs, and for GSK-3 $\beta$ were upregulated in in the AD patients' brain (Figure 5).
NFTs, one of the neuropathological hallmarks of AD, are composed of bundles of paired helical filaments, the major protein subunit of which is abnormally phosphorylated $\tau$, the microtubule-associated protein. ${ }^{39}$ Hyperphosphorylated $\tau$ forms NFTs, one of the hallmarks of AD, and leads to apoptosis by disrupting cytoskeletal and axonal transport. ${ }^{40}$ GSK-3 $\beta$ has been identified as a primary kinase in this process among several protein kinases including cdc2, cdk5 and MAP kinases. ${ }^{23}$ The changes in the levels of phosphorylated $\tau$ were examined by using AT8 antibody, which recognizes phosphorylated $\tau$ at its $\mathrm{Ser}^{202}$ and $\mathrm{Thr}^{205}$ sites. APLP2-ICDs were found to increase $\tau$ phosphorylation in PC12 cells and rat primary cultured neurons, whereas the Y738G point mutated APLP2-ICDs (C57 ${ }^{\text {Y738G }}$, C50 $\left.^{\text {Y738G }}\right)$ did not.

Here, we demonstrate that APLP2-ICDs induce GSK-3 $\beta$ expression, through interaction with the CP2 transcription factor in the nucleus, followed by subsequent $\tau$ phosphorylation. These findings suggest that APLP2-ICDs may contribute to $A D$ pathogenesis.

\section{Materials and Methods}

Materials. Lithium chloride and Hoechst 33258 were purchased from SigmaAldrich (MO, USA); Indirubin-3'-monoxime, 5-iodo and DAPT $\{N-[N-(3$, 5difluorophenacetyl)-L-alanyl]-S-phenylglycine $t$-butyl ester\}, from Calbiochem (Darmstadt, Germany). Anti-GFP monoclonal antibody was obtained from BD Biosciences (CA, USA); anti-APLP2, C-terminal polyclonal antibody (C12; against last 12 amino acids of the $\mathrm{C}$-terminus of APLP2) was a generous gift from $\mathrm{Dr}$ Gopal Thinakaran at the University of Chicago. Anti-CP2 serum was a generous gift from Dr. Roeder of Rockefeller University. Anti-Flag M5 monoclonal antibody was purchased from Sigma-Aldrich (MO, USA); anti-human $\mathrm{p}-\tau$ monoclonal antibody, clone AT8, from Innogenetics (Belgium), anti-APLP2 (C-17) antibody, which recognizes APLP2 N-terminal extracellular domain, anti-GSK-3 $\beta$, anti-p-GSK-3 $\beta$ $\left(\mathrm{Tyr}^{216}\right)$ and anti- $\tau$ antibodies were obtained from Santa Cruz Biotechnology, Inc. (CA, USA)

DNA constructs and mutagenesis. Mouse APLP2-751 cDNA in the pCB6 vector was a kind gift from Dr Gopal Thinakaran at the University of Chicago. Rat Fe65 cDNA in the pcDNA3 vector was kindly provided by Dr Joseph, D Buxbaum at Mount Sinai School of Medicine. The cDNA constructs encoding different lengths of the APLP2-ICDs were produced as follows (Schematic diagrams of the APLP2ICDs are shown in Figure 1A). The constructs were generated by PCR from mouse APLP2-751 cDNA to encompass the last 57 or 50 amino-acid residues. The amplified cDNAs were subcloned into Xhol and BamHI sites of the pEGFP-N1 eukaryotic expression vector (BD Biosciences, CA, USA). To construct Y738G of C57 or -C50, we used a QuickChange Site-Directed Mutagenesis Kit (Stratagene, CA, USA). The GFP-GFP expression vector was generated by cloning in the BamHI-Agel sites of the pEGFP-N1 vector (BD Biosciences, CA, USA). The EGFP CDNA was obtained by direct amplification from the same vector. The C57-GFPGFP was obtained by cutting C57 cDNA from Xhol and BamHI sites and inserted into the same sites of the GFP-GFP vector prepared as described above. YFP-C57 or YFP-C57 with point mutation Y738G was prepared by transferring the Xhol, BamHI cut fragment of $\mathrm{C} 57$ or its point mutation cloned in the pEGFP-N1 vector to the pEYFP-C1 vector (BD Biosciences, CA, USA). CFP-CP2 construct was generated by $\mathrm{PCR}$ from mouse $\mathrm{CP} 2$ in the $\mathrm{pRc}$ vector. All constructs were sequenced using an $A B \mid 310$ Sequencer.

Cell culture and transfection. SH-SY5Y and HEK293 cells were plated in a six-well plate maintained in Dulbecco's modified Eagle's medium (DMEM, Life Technologies, NY, USA) supplemented with $10 \%$ fetal bovine serum (FBS) and $0.3 \%$ antibiotics at $37^{\circ} \mathrm{C}$ and $5 \% \mathrm{CO}_{2}$. PC12 cells originating from rat pheochromocytoma were plated on a polyethyleneimine (PEl, $0.2 \mathrm{mg} / \mathrm{ml}$, SigmaAldrich, MO, USA) coated plates and maintained in DMEM supplemented with $10 \%$ FBS (GIBCO BRL, NY, USA) and $0.3 \%$ antibiotics at $37{ }^{\circ} \mathrm{C}$ in $5 \% \mathrm{CO}_{2}$. PC12 cells were treated with nerve growth factor (NGF, $50 \mathrm{ng} / \mathrm{ml}$ ) from Calbiochem (Darmstadt, 
Germany) to differentiate for 4 days. The cerebral cortex was dissected out of Sprague-Dawley rat embryo at embryonic day 17 and dissociated by gentle trituration. Cells were plated on PEI coated plates and after overnight incubation in DMEM supplemented with $10 \%$ FBS, the medium was changed to a serum-free medium as defined for neurons (neurobasal medium supplemented with B27 and penicillin-streptomycin-amphotericin B mixture (Gibco BRL)). Experiments were performed in 14- to 15-day cultures. HEK293 cells, NGF differentiated PC12 cells and rat cortical primary neurons were transiently transfected with $2 \mu \mathrm{g}$ of plasmid DNA and $3 \mu \mathrm{l}$ of Fugene 6 (Roche Molecular Biochemicals, Germany) in $1 \mathrm{ml}$ of growing medium, according to the manufacturer's instruction.

Nuclear and cytosolic fractionation. At 48-h post-transfection, cells plated on six-well plates were washed with ice-cold PBS and then nuclear and cytoplasmic fractionation was performed, according to the manufacturer's protocol (Nuclear and Cytoplsmic Extraction Reagents; PIERCE, IL, USA).

Immunoprecipitation. A measure of $100 \mu \mathrm{g}$ of samples in $1 \mathrm{ml}$ lysis buffer were rotated with Protein G Plus/Protein A agarose (Oncogene, Darmstadt, Germany) for $1 \mathrm{~h}$ at $4^{\circ} \mathrm{C}$, and then centrifuged at 14000 r.p.m. for $20 \mathrm{~min}$. Supernatants were incubated with $1 \mu \mathrm{g}$ of primary antibody with rotation for $1 \mathrm{~h}$ at $4^{\circ} \mathrm{C}$, treated with Protein G Plus/Protein A agarose for $1 \mathrm{~h}$ at $4^{\circ} \mathrm{C}$, and centrifuged at 14000 r.p.m. for $20 \mathrm{~min}$. The pellet was boiled for $7 \mathrm{~min}$ in sample buffer $(0.2 \mathrm{M}$ Tris$\mathrm{HCl} \mathrm{pH} 6.8,10 \%$ SDS, 25\% glycerol and $0.01 \%$ bromophenol blue) and then centrifuged at 13000 r.p.m. for $15 \mathrm{~min}$. The supernatant was subjected to SDS polyacrylamide gel electrophoresis.

Western blotting. Protein was resolved in SDS polyacrylamide gel and electrophoresis was performed at $30-50 \mu \mathrm{g}$ of protein/lane, and transferred onto a nitrocellulose membrane (Amersham Pharmacia, Buckinghamshire, UK). The protein blot was proved with appropriate antibodies and then detected with horseradish peroxidase-conjugated secondary antibody (Amersham Pharmacia). The immunoreactive bands were visualized using an ECL enhanced chemiluminescence system (ECL; Amersham Pharmacia, Buckinghamshire, UK).

Fluorescence resonance energy transfer. FRET measurements were observed using Zeiss LSM 510 confocal microscope mounted on Zeiss Axiovert 200 inverted microscope. FRET was measured employing a method developed for laser scanning confocal microscopy using an argon laser to excite EYFP or ECFP. ${ }^{41-43}$ HEK293 cells on six-well plates were co-transfected with YFP vector, YFP-C57, or

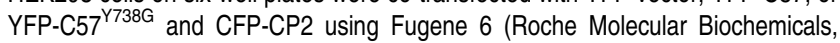
Germany). At $24 \mathrm{~h}$ after transfection, the coverslips were mounted on Axiovert 200 inverted microscope (Zeiss, Jena Germany). Initial scan was obtained at low energy using the $458 \mathrm{~nm}$ line of the argon laser to record the ECFP signal. A second scan was performed with the $568 \mathrm{~nm}$ line, and cells of colocalization was noted. Cells was then photobleached with intense $514 \mathrm{~nm}$ light (laser power 100\%) to destroy the acceptor molecules. The energy transfer was detected as an increase in donor fluorescence (ECFP) after complete photobleaching of the acceptor molecules (EYFP) at $514 \mathrm{~nm}$. The amount of energy transfer was calculated as the percent increase in donor fluorescence after acceptor photobleaching. An increase of the ECFP signal within the photobleached area was used as a measure of the amount of FRET present.

Cell viability assay. LDH activities in the conditioned media were measured using a CytoTox 96 Non-Radioactive Cytotoxicity Assay kit (Promega, WI, USA), according to the manufacturer's instructions and absorbance was measured at $490 \mathrm{~nm}$ using a microplate reader (Molecular Devices, Sunnyvale, CA, USA).

Evaluation of apoptosis with Hoechst dye staining. Hoechst 33258 (Sigma-Aldrich, MO, USA) was used to assess chromatin condensation as published, previously. ${ }^{44}$

Immunocytochemistry. Cells were fixed in $4 \%$ paraformaldehyde for $1 \mathrm{~h}$ at $4^{\circ} \mathrm{C}$ and then for $30 \mathrm{~min}$ at room temperature. After quenching the cells in $50 \mathrm{~mm}$ $\mathrm{NH}_{4} \mathrm{Cl}-\mathrm{PBS}$ for $10 \mathrm{~min}$, they were washed in PBS and permeabilized for $30 \mathrm{~min}$ at room temperature in PBS containing $0.1 \%$ Triton $X-100$ and $1 \mathrm{mg} / \mathrm{ml}$ bovine serum albumin (permeabilization buffer). The following steps were performed at room temperature in permeabilization buffer. Cells were incubated with appropriate primary antibodies for $1 \mathrm{~h}$. After three washes, primary antibodies were revealed by incubating the cells for $1 \mathrm{~h}$ with FITC or Cy3 conjugated secondary antibodies
(Jackson ImmunoResearch, PA, USA). After three washes in permeabilization buffer and one wash in PBS, the cells were mounted on microscope slide in mounting medium (DAKO, Carpinteria, CA, USA), including DAPI $(1 \mu \mathrm{M})$ for mounting and nucleus staining. Cells were observed under a confocal microscopy (LSM 510, Zeiss, Germany).

Reverse transcription polymerase chain reaction (RT-PCR) analysis. Total RNA was isolated using the easy-BLUE ${ }^{\mathrm{TM}}$ RNA Extraction Kit (iNtRON Biotechnology, Seoul, Korea) from cells. RNA was reverse transcribed with random primer (Gibco BRL, NY, USA) and Superscript II reverse transcriptase (Gibco BRL, NY, USA). PCR was then carried out using a Gene Cycler (BioRad, Hercules, CA, USA), with a denaturation step of $94^{\circ} \mathrm{C} / 5 \mathrm{~min}$ followed by 25 cycles of $95^{\circ} \mathrm{C} / 1 \mathrm{~min}, 57^{\circ} \mathrm{C} / 1 \mathrm{~min}$ and $72^{\circ} \mathrm{C} / 2 \mathrm{~min}$ and a final extension step of $72^{\circ} \mathrm{C} / 10 \mathrm{~min}$. The primer pairs used to amplify rat GSK- $3 \beta$ were forward: $5^{\prime}$ GGA TCT GCC ATC GAG ACA TT3'; reverse: 5'CCA ACT GAT CCA CAC CAC TG3'.

Luciferase activity assay. Human GSK-3 $\beta$ promoter (nt -2090 to $\sim n t+1035$ ) in the pCAT vector was a kind gift from Dr PC Shaw at the Chinese University of Hong Kong. The promoter region in the vector was excised at $K P n l$ and $B g 11$ sites and inserted into the KPnl and Bg1ll sites of PGL2 promoter plasmid (Promega, WI, USA). For co-transfection experiments, $4 \mu \mathrm{g}$ of human GSK$3 \beta$ promoter in the PGL2 vector and APLP2-ICDs (C57, C50, C57 ${ }^{\text {Y738G }}$ or $\mathrm{C} 50^{\mathrm{Y} 738 \mathrm{G}}$ ) in the pEGFPN1 vector were added to the PC12 cells. Luciferase activity was measured using a Biocounter M1500 luminometer (Lumac, GE Groningen, Netherlands). Luciferase activities were normalized versus the obtained protein concentrations.

Immunohistochemistry. $A D$ and age-matched control brains were obtained from the autopsy service at University of Oklahoma Heath Sciences Center, USA and Korea Scientific Investigation Center. A neuropathological diagnosis of AD was confirmed according to the criteria of Braak. ${ }^{25}$ Blocks of $A D$ or control tissue were fixed in $10 \%$ neutral buffered formalin for $48 \mathrm{~h}$. After fixation, the brain tissue was dehydrated and embedded in paraffin. Immunohistochemistry was performed using a Vectastain avidin-biotin complex (ABC) elite kit (Vector, Burlingame, CA, USA) as described previously. ${ }^{45}$ Images were captured using an optical microscope (BX51TF, Olympus Optical Co., Japan) equipped with an exposure control unit (PMCB20) and a camera (CPM-C35DX).

Statistical analysis. Results are presented as means \pm s.e.m. All statistical analysis was performed using SPSS for Windows 10.0.7 software (SPSS Inc., Chicago, USA). One-way ANOVA test was used to study the relationship between the different variables. $p<0.05$ was considered to be significant.

\section{Acknowledgements}

We are grateful to Drs. Gopal Thinakaran and Vincenzo Casolaro at the University of Chicago and Johns Hopkins University for providing the APLP2 cDNA, antiserum and CP2 cDNA, respectively. We also thank Drs Joseph D Buxbaum at Mount Sinai School of Medicine and Pang-Chui Shaw for providing rat Fe65 cDNA and human glycogen synthase kinase $3 \beta$ promoter, respectively. This work was supported by a National Creative Research Initiative Grant (2003-2005) from MOST, in part by the BK21 Human Life Sciences program and by a grant from Seoul National University Bundang Hospital Research Fund.

1. Wang P, Yang G, Mosier DR, Chang P, Zaidi T, Gong YD et al. Defective neuromuscular synapses in mice lacking amyloid precursor protein (APP) and APP-Like protein 2. J Neurosci 2005; 25: 1219-1225.

2. Daigle I, Li C. apl-1, a Caenorhabditis elegans gene encoding a protein related to the human beta-amyloid protein precursor. Proc Natl Acad Sci USA 1993; 90: 12045-12049.

3. Rosen DR, Martin-Morris L, Luo LQ, White K. A Drosophila gene encoding a protein resembling the human beta-amyloid protein precursor. Proc Natl Acad Sci USA 1989; 86 2478-2482.

4. Tanzi RE, St George-Hyslop PH, Gusella JF. Molecular genetic approaches to Alzheimer's disease. Trends Neurosci 1989; 12: 152-158.

5. Wasco W, Bupp K, Magendantz M, Gusella JF, Tanzi RE, Solomon F. Identification of a mouse brain CDNA that encodes a protein related to the Alzheimer disease-associated amyloid beta protein precursor. Proc Natl Acad Sci USA 1992; 89: 10758-10762.

6. Wasco W, Gurubhagavatula S, Paradis MD, Romano DM, Sisodia SS, Hyman BT et al. Isolation and characterization of APLP2 encoding a homologue of the Alzheimer's associated amyloid beta protein precursor. Nat Genet 1993; 5: 95-100. 
7. Slunt HH, Thinakaran G, von Koch C, Lo ACY, Tanzi RE, Sisodia SS. Expression of a ubiquitous, cross-reactive homologue of the mouse beta-amyloid precursor protein (APP). J Biol Chem 1994; 269: 2637-2644.

8. Walsh DM, Fadeeva JV, Lavoie MJ, Paliga K, Egger S, Kimberly WT et al. Gammasecretase cleavage and binding to FE65 regulate the nuclear translocation of the intracellular C-terminal domain (ICD) of the APP family of proteins. Biochemistry 2003; 42 : 6664-6673.

9. Kim TW, Wu K, Xu JL, McAuliffe G, Tanzi RE, Wasco W et al. Selective localization of amyloid precursor-like protein 1 in the cerebral cortex postsynaptic density. Brain Res Mol Brain Res 1995; 32: 36-44.

10. Scheinfeld MH, Ghersi E, Laky K, Fowlkes BJ, D'Adamio L. Processing of beta-amyloid precursor-like protein-1 and -2 by gamma -secretase regulates transcription. $J$ Biol Chem 2002; 277: 44195-44201.

11. Cappai R, Mok SS, Galatis D, Tucker DF, Henry A, Beyreuther K et al. Recombinan human amyloid precursor-like protein 2 (APLP2) expressed in the yeast Pichia pastoris can stimulate neurite outgrowth. FEBS Lett 1999; 442: 95-98.

12. Crain $\mathrm{BJ}, \mathrm{Hu} W, \mathrm{Se} \mathrm{Cl}$, Slunt $\mathrm{HH}, \mathrm{Koo} \mathrm{EH}$, Price $\mathrm{DL}$ et al. Expression and distribution of amyloid precursor protein-like protein-2 in Alzheimer's disease and in normal brain. $A m \mathrm{~J}$ Pathol 1996; 149: 1087-1095.

13. Gu Y, Misonou H, Sato T, Dohmae N, Takio K, Ihara Y. Distinct intramembrane cleavage of the beta-amyloid precursor protein family resembling gamma-secretase-like cleavage of Notch. J Biol Chem 2001; 276: 35235-35238.

14. Eggert S, Paliga K, Soba P, Evin G, Masters CL, Weidemann A et al. The proteolytic processing of the amyloid precursor protein gene family members APLP-1 and APLP-2 involves alpha-, beta-, gamma-, and epsilon-like cleavages: modulation of APLP-1 processing by n-glycosylation. J Biol Chem 2004; 279: 18146-18156.

15. Russo T, Faraonio R, Minopoli G, De candia P, De Renzis S, Zambrano N. Fe65 and the protein network centered around the cytosolic domain of the Alzheimer's beta-amyloid precursor protein. FEBS Lett 1998; 434: 1-7.

16. Taylor AE, Yip A, Brayne C, Easton D, Evans JG, Xuereb J et al. Genetic association of an LBP-1C/CP2/LSF gene polymorphism with late onset Alzheimer's disease. J Med Genet 2001; 38: 232-233.

17. Lambert JC, Goumidi L, Vrieze FW, Frigard B, Harris JM, Cummings A et al. The transcriptional factor LBP-1C/CP2/LSF gene on chromosome 12 is a genetic determinant of Alzheimer's disease. Hum Mol Genet 2000; 9: 2275-2280

18. Thinakaran G, Kitt CA, Roskams AJ Slunt HH, Masliah E, von Koch C et al Distribution of an APP homolog, APLP2, in the mouse olfactory system: a potential role for APLP2 in axogenesis. J Neurosci 1995; 15: 6314-6326.

19. Zambrano N, Minopoli G, de Candia P, Russo T. The Fe65 adaptor protein interacts through its PID1 domain with the transcription factor CP2/LSF/LBP1. J Biol Chem 1998; 273: 20128-20133.

20. Lau KF, Miller CCJ, Anderton BH, Shaw PC. Molecular cloning and characterization of the human glycogen synthase kinase-3 $\beta$ promoter. Genomics 1999; 60: 121-128.

21. Bhat RY, Shanley J, Correll MP, Fieles WE, Keith RA, Scott CW et al. Regulation and localization of tyrosine 216 posphorylation of glycogen synthase-3beta in cellular and animal models of neuronal degeneration. Proc Natl Acad Sci USA 2000; 97: 11074-11079.

22. Buee L, Bussiere T, Buee-Scherrer V, Delacourtte A, Hof PR. Tau protein isoforms, phosphorylation and role in neurodegenerative disorders. Brain Res Rev 2000; 33: 95130.

23. Liu F, Lqbal K, Grundke-lqbal I, Gong CX. Involvement of aberrant glycosylation in phosphorylation of tau by cdk5 and GSK-3beta. FEBS Lett 2002; 530: 209-214.

24. Lucas JJ, Hernandez F, Gomez-Ramos P, Moran MA, Hen R, Avila J. Decreased nuclear beta-catenin, tau hyperphosphorylation and neurodegeneration in GSK-3beta conditional transgenic mice. EMBO J 2001; 20: 27-39.

25. Braak H, Braak E. Neuropathological staging of Alzheimer-related changes. Acta Neuropathol 1991; 82: 239-259.
26. Selkoe KJ. Alzheimer's disease: genes, proteins, and therapy. Physiol Rev 2001; 81: 741766.

27. Suh YH, Checler F. Amyloid precursor protein, presenilins, and alpha-synuclein: molecular pathogenesis and pharmacological applications in Alzheimer's disease. Pharmacol Rev 2002; 54: 469-525.

28. Pastorino L, Ikin AF, Lamprianou S, Vacaresse N, Revelli JP, Platt K et al. BACE (betasecretase) modulates the processing of APLP2 in vivo. Mol Cell Neurosci 2004; 25: 642649.

29. Li Q, Sudhof TC. Cleavage of amyloid-beta precursor protein and amyloid beta precursorlike protein by BACE 1. J Biol Chem 2004; 279: 10542-10550.

30. Endres K, Postina R, Schroeda A, Mueller U, Fahrenholz F. Shedding of the amyloid precursor protein-like protein APLP2 by disintegrin-metalloproteinases. FEBS J 2005; 272: 5808-5820.

31. Pardossi-Piquard R, Petit A, Kawarai T, Sunyach C, Alves C, Vincent B et al. Presenilindependent transcriptional control of the Abeta-degrading enzyme neprilysin by intracellular domains of betaAPP and APLP. Neuron 2005; 46: 541-554

32. Yoon JB, Li G, Roeder RG. Characterization of a family of related cellular transcription factors which can modulate human immunodeficiency virus type 1 transcription in vitro. $\mathrm{Mol}$ Cell Biol 1994; 14: 1776-1785.

33. Panza F, D'Introno A, Colacicco AM, Capurso C, Basile AM, Torres F et al. 2004 LBP-1C/ CP2/LSF gene polymorphism and risk of sporadic Alzheimer's disease. I Neurosurg Psychiatry 75: 166-168.

34. Grimes CA, Jope RS. The multifaceted roles of glycogen synthase kinase 3 in cellular signaling. Prog Neurobiol 2001; 65: 391-426.

35. Sato S, Tatebayashi Y, Akagi T, Chui DH, Murayama M, Miyasaka T et al. Aberrant tau phosphorylation by glycogen synthase kinase-3beta and JNK3 induces oligomeric tau fibrils in COS-7 cells. J Biol Chem 2002; 277: 42060-42065.

36. Kaytor MD, Orr HT. The GSK 3 beta signaling cascade and neurodegenerative disease. Curr Opin Neurobiol 2002; 12: 275-278.

37. Eldar-finkelmen $\mathrm{H}$. Glycogen synthase kinase 3 : an emerging therapeutic target. Trends Mol Med 2002; 8: 126-132.

38. Pei JJ, Braak E, Braak H, Grunde-Iqbal I, Iqbal K, Winblad B et al. Distribution of active glycogen synthase kinase 3 beta(GSK-3 beta) in brains staged for Alzheimer disease neurofibrillary changes. J Neuropathol Exp Neurol 1999; 58: 1010-1019.

39. Lee VM, Balin BJ, Otros LJ, Trojanowski JQ. A68: a major subunit of paired helical filaments and derivatized forms of normal tau. Science 1991; 251: 675-678.

40. Trojanowski JQ, Schmidt ML, Shin RW, Bramblett GT, Rao D, Lee VM. Altered tau and neurofilament proteins in neuro-degenerative diseases: diagnostic implications for Alzheimer's disease and Lewy body dementias. Brain Pathol 1993: 3: 45-54.

41. Knowles RB, Chin J, Ruff CT, Hyman BT. Demonstration by fluorescence resonance energy transfer of a close association between activated MAP kinase and neurofibriallry tangles: implications for MAP kinase activation in Alzheimer disease. J Neuropathol Exp Neurol 1999; 58: 1090-1098.

42. Mclean PJ, Kawamata H, Ribich S, Hyman BT. Membrane association and protein conformation of alphz-synuclein in intact neurons. Effect of Parkinson's disease-linked mutations. J Biol Chem 2000; 275: 8812-8816.

43. Kinoshita A, Whelan CJ, Smith O, Berezovsk O, Hyman BT 2002 Direct visualization of the gamma secretase-generated carboxyl-terminal domain of the amyloid precursor protein: association with Fe65 and translocation to the nucleus. Journal of Neurochem 82: 839847.

44. Telford WG, King LE, Fraker PJ. Comparative evaluation of several DNA binding dyes in the detection of apoptosis-associated chromatin degradation by flow cytometry. Cytometry 1992; 13: 137-143

45. Koo JW, Park CH, Choi SH, Kim NJ, Kim HS, Choe JC et al. The postnatal environment can counteract prenatal effects on cognitive ability, cell proliferation, and synaptic protein expression. FASEB J 2003; 17: 1556-1558. (doi:10.1096/fj.02-1032fje.).

Supplementary Information accompanies the paper on Cell Death and Differentiation website (http://www.nature.com/cdd) 